\title{
The Neurological Complications of Nutritional Deficiency following Bariatric Surgery
}

\author{
Danielle A. Becker, ${ }^{1}$ Laura J. Balcer, ${ }^{1,2,3}$ and Steven L. Galetta ${ }^{1,2}$ \\ ${ }^{1}$ Department of Neurology, Perelman School of Medicine, University of Pennsylvania, 3 W. Gates Building, 3400 Spruce Street, \\ Philadelphia, PA 19104, USA \\ ${ }^{2}$ Department of Ophthalmology, Perelman School of Medicine, University of Pennsylvania, 3 W. Gates Building, 3400 Spruce Street, \\ Philadelphia, PA 19104, USA \\ ${ }^{3}$ Department of Epidemiology, Perelman School of Medicine, University of Pennsylvania, 3 W. Gates Building, 3400 Spruce Street, \\ Philadelphia, PA 19104, USA
}

Correspondence should be addressed to Steven L. Galetta, Steve.Galetta@uphs.upenn.edu

Received 7 December 2011; Accepted 23 April 2012

Academic Editor: Sayeed Ikramuddin

Copyright ( 92012 Danielle A. Becker et al. This is an open access article distributed under the Creative Commons Attribution License, which permits unrestricted use, distribution, and reproduction in any medium, provided the original work is properly cited.

Neurologic complications of bariatric surgery have become increasingly recognized with the rising numbers of procedures and the increasing prevalence of obesity in the US. Deficits are most commonly seen with thiamine, vitamin $B_{12}$, folate, vitamin $\mathrm{D}$, vitamin $\mathrm{E}$, and copper deficiencies. The neurological findings observed with these nutritional deficiencies are variable and include encephalopathy, optic neuropathy, myelopathy, polyradiculoneuropathy, and polyneuropathy. We review the neurological complications of bariatric surgery and emphasize that these findings may vary based on the specific type of bariatric surgery and time elapsed from the procedure.

\section{Introduction}

The rate of obesity continues to rise and affects more than one-third of the US adult population (over 72 million people) [1]. One of the most effective treatments for obesity and its associated comorbidities is bariatric surgery because of its dramatic and durable results. According to the American Society for Metabolic and Bariatric Surgery, the number of bariatric surgeries has increased more than 10 fold, from 16,000 in the early 1990 s to approximately 220,000 in 2008 [2]. However, as the prevalence of obesity and the numbers of patients undergoing bariatric surgeries rise, the incidence and recognition of neurologic complications from bariatric surgery also continues to increase. There is a growing literature to support the effectiveness of bariatric surgery in reducing morbidity and mortality for those with BMI $>40$ and for patients with BMI $>35$ and obesityrelated complications [3]. Further growth of this surgical field is supported by the recent FDA approval for the expanded use of the lap-band system to include patients with a minimum BMI of $35 \mathrm{~kg} / \mathrm{m}^{2}$ without comorbidities and 30 with comorbidities. Associated bariatric procedures contribute to nutritional deficiencies by restricting food intake and/or limiting intestinal absorption. The forms of surgery that are solely restrictive include gastric banding and vertical banding. The procedures that are restrictive and produce malabsorption include the Roux-en-Y gastric bypass procedure and the biliopancreatic diversion with duodenal switch. After these surgeries, patients should remain on high protein and low-fat diets with vitamin supplementation and have nutritional and metabolic blood tests performed on a frequent basis. In addition, it is important to note that nutritional recommendations and complications tend to be associated with the specific type of bariatric surgical procedure performed (Tables 1 and 2) [4-6].

Neurologic complications of bariatric surgery have an estimated incidence of up to $16 \%$ per year and need to be discussed with patients who are considering surgery [7]. Neurological deficits are most commonly associated with nutritional deficiencies that develop following surgery. The most commonly described nutritional deficiencies include 


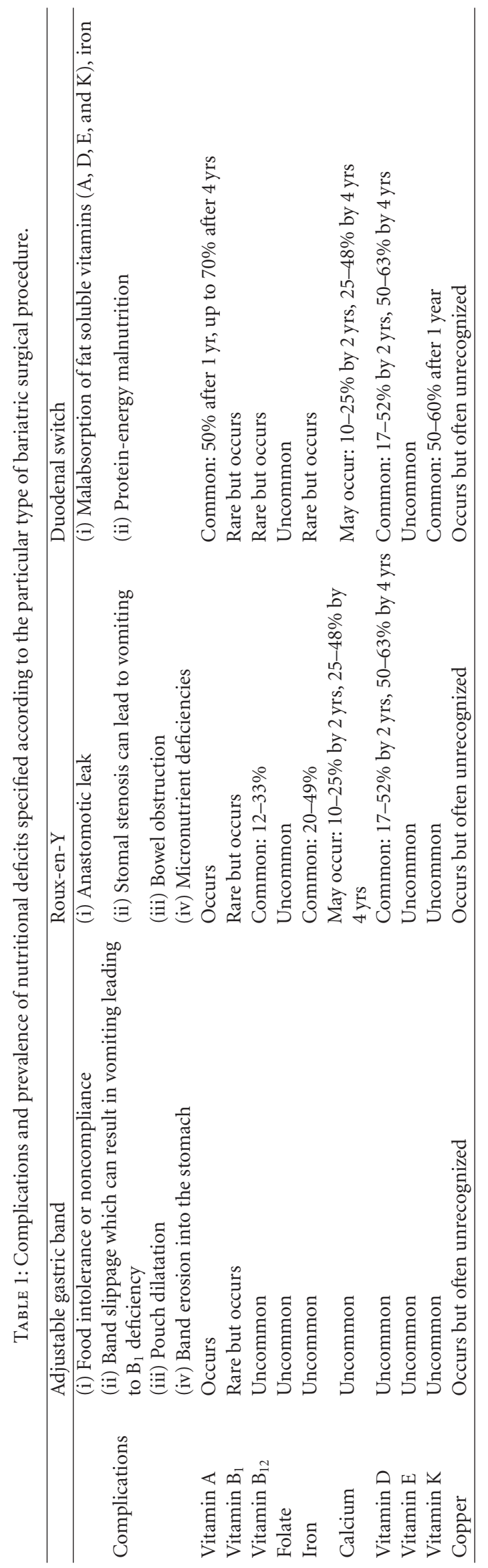




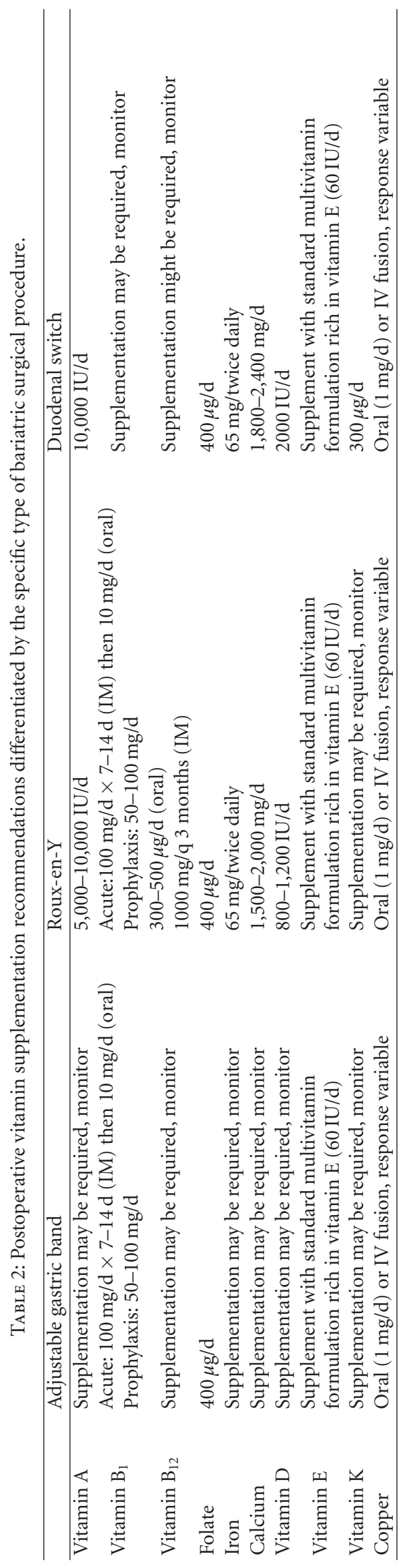


TABLE 3: Specific neurological complications associated with vitamin deficiencies after bariatric surgery.

\begin{tabular}{lcl}
\hline Vitamin/nutrient & Incidence & Complications \\
\hline Vitamin A & $10 \%$ & Xerophthalmia, night blindness, and decreased immunity \\
Vitamin $\mathrm{B}_{1}$ & "Common" & Wernicke's encephalopathy, Korsakoff syndrome, and Beriberi \\
Vitamin $\mathrm{B}_{12}$ & $<1 \%$ symptomatic & (dry/wet) \\
Folate & $30-70 \%$ & Myelopathy, neuropathy, dementia, and depression \\
Vitamin D & $1-10 \%$ & Macrocytic anemia and fatigue may aggravate $\mathrm{B}_{12}$ deficiency \\
Vitamin E & $50-60 \%$ & Myopathy \\
Copper & Rare & Peripheral neuropathy, myopathy \\
Vitamin $\mathrm{B}_{2}$ & Rare because undiagnosed & Myelopathy, sensory ataxia \\
Vitamin $\mathrm{B}_{6}$ & $14 \%$ & Burning feet syndrome \\
\hline
\end{tabular}

thiamine $\left(\mathrm{B}_{1}\right), \mathrm{B}_{12}$, folate, vitamin $\mathrm{D}$, vitamin $\mathrm{E}$, and copper deficiencies [3]. Risk factors for nutritional complications include vitamin noncompliance, protracted vomiting, and excessive alcohol consumption $[3,8]$. The associated complications can involve many areas of the nervous system and include encephalopathy, optic neuropathy, myelopathy, polyradiculoneuropathy, and polyneuropathy (Table 3) [3, 8]. As a preventative measure, guidelines suggest that patients (regardless of the type of procedure) should take multivitamins that contain $400 \mu \mathrm{g}$ of folate ( 1 to 2 tablets per day); calcium citrate (1,200-2,000 mg/d); vitamin D (400 to 800 units per day, but higher doses have been advocated in the range of 1000 to 2000 units per day); elemental iron (40$65 \mathrm{mg} / \mathrm{d})$; vitamin $\mathrm{B}_{12}(300-500 \mu \mathrm{g} / \mathrm{d}$ of the oral crystalline form; dose and route are dependent upon levels). The standard recommendation for postoperative supplementation for thiamine in symptomatic patients is $100 \mathrm{mg} / \mathrm{d} \times 7-$ $14 \mathrm{~d}$ (IM) and then $10 \mathrm{mg} / \mathrm{d}$ (oral) until complete recovery of neurologic symptoms. The standard recommendation for daily oral supplementation after surgery in asymptomatic patients is $50-100 \mathrm{mg} / \mathrm{d}$ (Table 2) $[4-6,9,10]$.

\section{Vitamin Deficiencies}

2.1. Thiamine $\left(B_{1}\right)$. Thiamine deficiency can occur within 8 to 15 weeks after surgery but has been reported as early as 6 weeks $[11,12]$. The mechanism is related to inadequate vitamin repletion along with persistent, intractable vomiting [13]. Deficiency can occur despite oral supplementation if emesis is present because it prevents effective absorption. Vitamin $B_{1}$ deficiency can cause lactic acidosis, reduced oxygen uptake, and depression of transketolase activity [14]. It alters mitochondrial function by impairing oxidative metabolism and diminishes vitamin $\mathrm{B}_{1}$-dependent enzymes, resulting in selective neuronal cell death [15]. Thiamine deficiency is pertinent in the development of both acute and chronic encephalopathies such as Wernicke's encephalopathy and Korsakoff's syndrome. Wernicke's encephalopathy is associated with nutritional polyneuropathy (dry beriberi), ophthalmoparesis and nystagmus, ataxia, and confusion. Permanent impairment of recent memory, known as Korsakoff's syndrome, may result [14]. Recovery typically occurs within 3 to 6 months of initiation of therapy if the symptoms are recognized early [16]. If thiamine deficiency is not discovered early, patients may be left with permanent deficits including ocular motility abnormalities, ataxia, and mental status changes.

2.2. Cobalamin (Vitamin $B_{12}$ ). Deficient vitamin $B_{12}$ levels may not appear for several years after bariatric surgery, since liver stores are sufficient to provide for years after initial dietary insufficiency. Low vitamin $\mathrm{B}_{12}$ levels following gastric bypass have been associated with inadequate intake, impaired hydrolysis of dietary protein, and defects in the amount of intrinsic factor or the interaction between intrinsic factor and vitamin $\mathrm{B}_{12}[17,18]$. The absorption of vitamin $\mathrm{B}_{12}$ requires the intrinsic factor derived from gastric parietal cells, acidic gastric $\mathrm{pH}$, and absorption in the ileum, any or all of which may be disrupted after bariatric surgery [13]. Neurologic symptoms commonly seen with $\mathrm{B}_{12}$ deficiency include paresthesias, weakness, decreased reflexes, spasticity, ataxia, position and vibratory sense loss, incontinence, loss of vision from optic nerve injury, dementia, psychosis, and altered $\operatorname{mood}[19,20]$. Severe autonomic symptoms may also rarely occur [21]. The initiation of vitamin $B_{12}$ supplementation within 6 months postoperatively is recommended by most surgical groups in the absence of controlled studies. Oral crystalline vitamin $B_{12}$ at a dose of at least $350 \mathrm{mg} / \mathrm{d}$ has been shown to maintain normal plasma vitamin $\mathrm{B}_{12}$ levels $(78-80)[4,5]$. Optimal dosing of oral, sublingual, or intranasal forms of $\mathrm{B}_{12}$ supplementation has not been well studied.

2.3. Folate. Following gastric bypass, folate deficiency can be very rare, occurring in as few as $1 \%$ of patients [22]. Folate deficiency has been associated with peripheral neuropathy and myelopathy [23]. Oral folic acid supplementation (400$500 \mu \mathrm{g} /$ day; recommended $1 \mathrm{mg}$ daily) has been shown to be effective in maintaining levels within the reference range $[4,5,24,25]$. However, folate supplementation can mask underlying $\mathrm{B}_{12}$ deficiency, leading to the progression of neurological damage [25].

2.4. Vitamin D. Vitamin D deficiency has been associated with secondary hypocalcemia after gastric bypass and is commonly associated with complaints of chronic nonspecific musculoskeletal pain. Marinella described a patient who developed symptoms of intermittent facial twitching and 
ophthalmoplegia in the setting of hypocalcemia years after gastric bypass surgery [26]. The patient responded to calcium repletion. Myopathy has also been attributed to vitamin $D$ deficiency and has been shown to improve with treatment (400-800 units per day) [27], but higher daily doses of vitamin D (1000-2000 units) are frequently used in practice today. Even higher doses may be needed depending upon the level of malabsorption that exists. It is also important to note that vitamin D deficiency can contribute to hypocalcemia in patients who also have direct, primary calcium malabsorption issues. Both hypocalcemia and vitamin D deficiency lead to secondary hyperparathyroidism. Thus, potential calcium and vitamin $\mathrm{D}$ absorption deficits need to be considered and effectively treated in these patients. Suboptimal vitamin D levels are common and should be screened for presurgery by measuring 25-hydroxyvitamin D (25-D) levels. Doses of vitamin $\mathrm{D}$ and calcium should be adjusted by a qualified medical professional based on serum markers and measures of bone density. Recommended doses of elemental calcium after bariatric surgery range from 1200 to $2000 \mathrm{mg}$ daily, and these usually contain vitamin $\mathrm{D}$ as well $[4,5]$.

2.5. Vitamin E. Low vitamin E levels have been found 612 months after surgery but may not appear for $5-10$ years [26]. The most common findings associated with vitamin $\mathrm{E}$ deficiency include loss of deep tendon reflexes, truncal and limb ataxia, diminished perception of vibration and position, ophthalmoplegia, muscle weakness, ptosis, and dysarthria [28]. Saccadic eye movements may be slow, and progressive gaze impairment may occur. Some patients may have an impairment of medial rectus function and an associated nystagmus in the affected eye. Severe vitamin E deficiency has been associated with sensory axonopathy, radiculopathies, and peripheral neuropathies. Vitamin E neuropathy and myopathy are often treatable, and the recommended daily dose of vitamin E is $400 \mathrm{IU}$ daily [29-31]. The suggested supplementation in asymptomatic postsurgical patients is a standard multivitamin formulation rich in vitamin E [6].

2.6. Copper. Symptoms of copper deficiency are often indistinguishable from those occurring with vitamin $B_{12}$ deficiency. A myelopathy with spastic ataxic gait, symmetrically brisk lower extremity reflexes, loss of vibratory perception to the ankles, and distal pinprick and light touch sensation were reported in a patient 24 years after intestinal bypass surgery [32]. She had normal $B_{12}$ levels, and administration of intravenous copper resulted in clinical improvement in this patient. Other signs associated with copper deficiency include peripheral neuropathy, myeloneuropathy, optic neuropathy, central nervous system demyelination, myopathy, and myelo-opticoneuropathy [33-36].

\section{Early/Acute Symptoms of Vitamin Deficiencies}

3.1. Polyradiculoneuropathy. Polyradiculoneuropathy, often resembling Guillain-Barré syndrome (GBS) if rapidly progressive, has been associated with vitamin $B_{1}$ deficiency and has been seen as early as six weeks after surgery [12]. These patients tend to have axonal degeneration rather than demyelination and a normal CSF protein level [8]. Symptoms are often described as pain in the feet or low back with ascending paresthesias. The symptoms may then progress to leg weakness associated with ataxia, areflexia, and vibratory and proprioceptive sensory loss. Parenteral supplementation, especially with thiamine (100 mg), has also been shown to improve symptoms [8].

3.2. Encephalopathy. Encephalopathy is often an acute, early complication of bariatric surgery that may develop within a few months. Up to $40 \%$ of patients presenting with neurologic complications develop encephalopathy, many of whom are deficient in thiamine $[3,8]$. While $\mathrm{B}_{12}$ deficiency can present years after bariatric procedures, the onset of Wernicke's encephalopathy most commonly occurs during the weeks to months following surgery [37]. Symptoms of Wernicke's encephalopathy are typically preceded by malnutrition, which results from prolonged emesis, although vitamin noncompliance or increased alcohol consumption were also noted $[3,8]$. Some studies suggest a genetic predisposition to Wernicke's encephalopathy due to reduced transketolase activity, a thiamine-requiring enzyme $[8,38]$. Further research should seek to identify preoperative risk factors, such as genetic testing for transketolase activity, in an attempt to identify patients at risk for development of Wernicke's or other nutritional deficiency syndromes. In addition, MRI findings in postbariatric surgery patients may provide further support for the development of Wernicke's encephalopathy. MRI patterns in these patients have been described and often include T2 prolongation in dorsomedial thalami and periaqueductal gray matter, enhancement of the mammillary bodies, and occasional diffusion restriction [39]. Hemorrhage involving the fornix and anterior thalami has also been seen on MRI imaging of a patient with Wernicke's encephalopathy [40]. Patients with Wernicke's encephalopathy have been shown to respond to intravenous thiamine administration [41]. While the standard dose of thiamine for suspected deficiency associated with neurologic disease is $100 \mathrm{mg}$ intravenously (IV) or intramuscularly (IM), more aggressive replacement may be required. A dose of $500 \mathrm{mg}$ IV three times a day for 2-3 days, followed by $250 \mathrm{mg}$ IV daily until improvement, has been proposed [42, 43]. These doses should then be followed by an oral dose of 50-100 mg daily as long as the patient continues to have nausea, vomiting, diarrhea, and so forth [42]. Patients with a history of bariatric surgery who present with any signs of gastrointestinal distress should receive thiamine preventively [44].

\section{Subacute Symptoms}

Optic Neuropathy. Optic neuropathy is often associated with copper and $\mathrm{B}_{12}$ deficiencies and has been reported to present $1.5-3$ years after surgery $[3,8,11,33]$. Symptoms include blurred vision with central scotoma and other signs of optic neuropathy. Optic neuropathy is often associated with 
malabsorption; one patient was reported to have developed optic neuropathy 5 months after stopping $B_{12}$ injections, only to improve once injections of $B_{12}$ were resumed [8].

\section{Late Signs and Symptoms}

5.1. Myelopathy. Myelopathy in the setting of nutritional deficiency is commonly seen and frequently can be one of the most debilitating problems associated with bariatric surgery. The problem usually starts insidiously and later in the post-op course, on average 9 years after surgery. It is often attributed to $B_{12}$ deficiency but has also been associated with copper, folate, and vitamin E deficiencies $[8,11,36]$. Patients present with ataxic gait, spasticity with hyperreflexia, loss of proprioceptive and vibratory sensations, and loss of pinprick and temperature sensation. It has been shown that treatment with oral or parenteral supplementation is associated with improvement of symptoms $[8,36]$.

5.2. Peripheral Neuropathies. Peripheral neuropathies of various types have been documented after bariatric surgery. They usually present years later and progress insidiously and should be distinguished from the polyradiculopathies described above that may be seen early in the course following bariatric surgery. Symptoms involve distal, painful paresthesias ("burning feet syndrome") and loss of pinprick and temperature sensation. Vitamin deficiencies most commonly associated with peripheral neuropathies are vitamin $B_{1}$, vitamin $B_{6}$, vitamin $B_{12}$, vitamin $E$, and copper $[3,11]$. Patterns have included sensory-predominant polyneuropathy, motor-predominant polyneuropathy, sensory motor polyneuropathy, mononeuropathy, and radiculoneuropathy [7]. The polyneuropathies typically described are length dependent with an axonal pathophysiology. Polyneuropathy secondary to thiamine deficiency classically presents as a symmetric sensory motor axonal polyneuropathy primarily affecting the legs [45]. It is unclear whether nutritional polyneuropathy is due to isolated thiamine deficiency. The neuropathies seen in postbariatric surgery patients may be due to a combination of nutritional deficiencies, as patients are usually deficient in multiple micronutrients. Nutritional supplementation may only be partially helpful in improving the symptoms of malabsorption of vitamin $\mathrm{B}_{12}$, thiamine, and vitamin $\mathrm{E}[3,8]$. Physical therapy for peripheral neuropathy has also been recommended [13].

Mononeuropathy is also a very common development in patients who have undergone bariatric surgery. Carpal tunnel syndrome is the most common. Less common are ulnar neuropathy at the elbow and radial mononeuropathy. Peroneal neuropathy and lateral femoral cutaneous neuropathy have also been reported [3].

5.3. Myopathy. Myopathy is less frequently reported in the literature but has been observed in patients with decreased global protein, vitamin D deficiency, copper deficiency, or hypokalemia in the setting of bariatric or other gastric surgeries [11]. Thiamine, vitamin E, selenium, calcium, phosphate, and magnesium deficiencies have also been proposed as etiologies for nutrition-related myopathy [46].

\section{Discussion}

As the prevalence of obesity rises, the number of bariatric surgeries has also increased. Surgery has proved to be a favorable option for treatment because of its cosmetic and durable effects. However, there are a number of neurological complications that can result from bariatric surgery; these are often irreversible $[3,13]$. The development of these associated symptoms is not uncommon, and it is therefore important to discuss the potential for these complications with patients. In addition, patients should be educated about possible symptoms that may develop in the first few months after surgery. For example, if they experience acute symptoms of confusion, memory deficits, and rapid progressive weakness, they should notify their providers immediately, and there should be a low threshold for investigation of possible vitamin deficiencies. Preventative measures, including early vitamin supplementation presurgery and continuing postsurgery as well as frequent followup, are important in the management of these patients. Typical nutritional deficiencies reported include thiamine, $B_{12}$, folate, vitamin $\mathrm{D}$, vitamin $\mathrm{E}$, and copper deficiencies [3]. If a patient presents with any of the neurologic complications discussed above, vitamin deficiencies and metabolic derangements should be investigated immediately.

As the indication for bariatric surgery becomes less stringent, these procedures will likely continue to increase in popularity. Clinicians will need to recognize and manage neurologic complications that may appear years to decades after bariatric surgery. The clinical history, physical examination, biochemical findings, nerve conduction studies, biopsy, and response to therapy will help to come to the final diagnosis and treatment of patients presenting with associated neurologic complications after bariatric surgery. Thus, the importance of vitamin supplementation and patient education and their role in reducing neurologic complications is even more crucial than ever. Prevention of neurological complications after bariatric surgery will involve close followup with routine screening in addition to nutritional supplements. Routine monitoring of selected micronutrients every 6 months after surgery may help detect deficiencies before they become symptomatic and improve overall comorbidities of bariatric surgery.

\section{References}

[1] Centers for Disease Control and Prevention (CDC), Behavioral Risk Factor Surveillance System Survey Data, U.S. Department of Health and Human Services, Centers for Disease Control and Prevention, Atlanta, Ga, USA, 2007.

[2] American Society for Bariatric Surgery, "Longitudinal Assessment of Bariatric Surgery (LABS) October 5, 2011,” 2011, http://www.win.niddk.nih.gov/publications/labs.htm.

[3] B. M. Koffman, L. J. Greenfield, I. I. Ali, and N. A. Pirzada, "Neurologic complications after surgery for obesity," Muscle and Nerve, vol. 33, no. 2, pp. 166-176, 2006. 
[4] L. Aills, J. Blankenship, C. Buffington, M. Furtado, and J. Parrott, "ASMBS allied health nutritional guidelines for the surgical weight loss patient," Surgery for Obesity and Related Diseases, vol. 4, no. 5, pp. S73-S108, 2008.

[5] D. Heber, F. L. Greenway, L. M. Kaplan, E. Livingston, J. Salvador, and C. Still, "Endocrine and nutritional management of the post-bariatric surgery patient: an endocrine society clinical practice guideline," Journal of Clinical Endocrinology and Metabolism, vol. 95, no. 11, pp. 4823-4843, 2010.

[6] M. R. Matrana and W. E. Davis, "Vitamin deficiency after gastric bypass surgery: a review," Southern Medical Journal, vol. 102, no. 10, pp. 1025-1031, 2009.

[7] P. Thaisetthawatkul, M. L. Collazo-Clavell, M. G. Sarr, J. E. Norell, and P. J. B. Dyck, "A controlled study of peripheral neuropathy after bariatric surgery," Neurology, vol. 63, no. 8, pp. 1462-1470, 2004.

[8] K. Juhasz-Pocsine, S. A. Rudnicki, R. L. Archer, and S. I. Harik, "Neurologic complications of gastric bypass surgery for morbid obesity," Neurology, vol. 68, no. 21, pp. 1843-1850, 2007.

[9] J. I. Mechanick, R. F. Kushner, H. J. Sugerman et al., "American association of clinical endocrinologists, the obesity society, and American society for metabolic \& bariatric surgery medical guidelines for clinical practice for the perioperative nutritional, metabolic, and nonsurgical support of the bariatric surgery patient," Surgery for Obesity and Related Diseases, vol. 4, no. 5, pp. S109-S184, 2008.

[10] B. M. Rhode and L. D. MacLean, "Vitamin and mineral supplementation after gastric bypass," in Update: Surgery for the Morbidly Obese Patient, M. Deitel and G. S. M. Cowan Jr., Eds., pp. 161-170, FD Communications, Toronto, Canada, 2000.

[11] L. D. Kramer and G. E. Locke, "Wernicke's encephalopathy. Complication of gastric plication," Journal of Clinical Gastroenterology, vol. 9, no. 5, pp. 549-552, 1987.

[12] E. Sola, C. Morillas, S. Garzon, J. M. Ferrer, J. Martin, and A. Hernandez-Mijares, "Rapid onset of Wernicke's encephalopathy following gastric restrictive surgery," Obesity Surgery, vol. 13, no. 4, pp. 661-662, 2003.

[13] J. R. Berger, "The neurological complications of bariatric surgery," Archives of Neurology, vol. 61, no. 8, pp. 1185-1189, 2004.

[14] P. M. Dreyfus and M. Victor, "Effects of thiamine deficiency on the central nervous system," The American Journal of Clinical Nutrition, vol. 9, pp. 414-425, 1961.

[15] Z. J. Ke, L. A. DeGiorgio, B. T. Volpe, and G. E. Gibson, "Reversal of thiamine deficiency-induced neurodegeneration," Journal of Neuropathology and Experimental Neurology, vol. 62, no. 2, pp. 195-207, 2003.

[16] H. Koike, K. Misu, N. Hattori et al., "Postgastrectomy polyneuropathy with thiamine deficiency," Journal of Neurology Neurosurgery and Psychiatry, vol. 71, no. 3, pp. 357-362, 2001.

[17] L. V. Crowley, J. Seay, and G. Mullin, "Late effects of gastric bypass for obesity," American Journal of Gastroenterology, vol. 79, no. 11 , pp. 850-860, 1984.

[18] J. D. Halverson, "Micronutrient deficiencies after gastric bypass for morbid obesity," American Surgeon, vol. 52, no. 11, pp. 594-598, 1986.

[19] J. Lindenbaum, E. B. Healton, D. G. Savage et al., "Neuropsychiatric disorders caused by cobalamin deficiency in the absence of anemia or macrocytosis," The New England Journal of Medicine, vol. 318, no. 26, pp. 1720-1728, 1988.
[20] E. B. Healton, D. G. Savage, J. C. M. Brust, T. J. Garrett, and J. Lindenbaum, "Neurologic aspects of cobalamin deficiency," Medicine, vol. 70, no. 4, pp. 229-245, 1991.

[21] P. Puntambekar, M. M. Basha, I. T. Zak, and R. Madhavan, "Rare sensory and autonomic disturbances associated with vitamin B12 deficiency," Journal of the Neurological Sciences, vol. 287, no. 1-2, pp. 285-287, 2009.

[22] G. N. Mallory and A. M. Macgregor, "Folate status following gastric bypass surgery (the great folate mystery)," Obesity Surgery, vol. 1, no. 1, pp. 69-72, 1991.

[23] L. M. Boylan, H. J. Sugerman, and J. A. Driskell, "Vitamin E, vitamin B-6, vitamin B-12, and folate status of gastric bypass surgery patients," Journal of the American Dietetic Association, vol. 88, no. 5, pp. 579-585, 1988.

[24] R. E. Brolin, R. C. Gorman, L. M. Milgrim, and H. A. Kenler, "Multivitamin prophylaxis in prevention of postgastric bypass vitamin and mineral deficiencies," International Journal of Obesity, vol. 15, no. 10, pp. 661-667, 1991.

[25] M. R. Matrana and W. E. Davis, "Vitamin deficiency after gastric bypass surgery: a review," Southern Medical Journal, vol. 102, no. 10, pp. 1025-1031, 2009.

[26] M. A. Marinella, "Ophthalmoplegia: an unusual manifestation of hypocalcemia," American Journal of Emergency Medicine, vol. 17, no. 1, pp. 105-106, 1999.

[27] N. K. Banerji and L. J. Hurwitz, "Nervous system manifestations after gastric surgery," Acta Neurologica Scandinavica, vol. 47, no. 4, pp. 485-513, 1971.

[28] R. J. Sokol, "Vitamin E deficiency and neurologic disease," Annual Review of Nutrition, vol. 8, pp. 351-373, 1988.

[29] M. A. Guggenheim, S. P. Ringel, A. Silverman, B. E. Grabert, and H. E. Neville, "Progressive neuromuscular disease in children with chronic cholestasis and vitamin E deficiency: clinical and muscle biopsy findings and treatment with $\alpha$ tocopherol," Annals of the New York Academy of Sciences, vol. 393, pp. 84-95, 1982.

[30] J. Nelson, "Neuropathological studies of chronic vitamin E deficiency in mammals including humans," in Biology of Vitamin E, R. Porter and J. Whelan, Eds., pp. 92-105, Pitman, London, UK, 1983.

[31] S. A. Rudnicki, "Prevention and treatment of peripheral neuropathy after bariatric surgery," Current Treatment Options in Neurology, vol. 12, no. 1, pp. 29-36, 2010.

[32] N. Kumar, K. M. McEvoy, and J. E. Ahlskog, "Myelopathy due to copper deficiency following gastrointestinal surgery," Archives of Neurology, vol. 60, no. 12, pp. 1782-1785, 2003.

[33] S. L. Pineles, C. A. Wilson, L. J. Balcer, R. Slater, and S. L. Galetta, "Combined optic neuropathy and myelopathy secondary to copper deficiency," Survey of Ophthalmology, vol. 55, no. 4, pp. 386-392, 2010.

[34] R. T. Naismith, J. B. Shepherd, C. C. Weihl, N. T. Tutlam, and A. H. Cross, "Acute and bilateral blindness due to optic neuropathy associated with copper deficiency," Archives of Neurology, vol. 66, no. 8, pp. 1025-1027, 2009.

[35] C. I. Prodan, S. S. Bottomley, A. S. Vincent et al., "Copper deficiency after gastric surgery: a reason for caution," American Journal of the Medical Sciences, vol. 337, no. 4, pp. 256-258, 2009.

[36] N. Kumar, J. B. Gross, and J. E. Ahlskog, "Copper deficiency myelopathy produces a clinical picture like subacute combined degeneration," Neurology, vol. 63, no. 1, pp. 33-39, 2004.

[37] R. K. Shin, S. L. Galetta, and S. G. Imbesi, "Wernicke encephalopathy," Archives of Neurology, vol. 57, no. 3, p. 405, 2000.

[38] T. Shimomura, E. Mori, N. Hirono, T. Imamura, and H. Yamashita, "Development of Wernicke-Korsakoff syndrome 
after long intervals following gastrectomy," Archives of Neurology, vol. 55, no. 9, pp. 1242-1245, 1998.

[39] N. Kumar, "Copper deficiency myelopathy (human swayback)," Mayo Clinic Proceedings, vol. 81, no. 10, pp. 1371-1384, 2006.

[40] B. Nazarov, S. Jeannin, M. Mejdoubi et al., "Teaching Neuroimages: bilateral anterior thalami and fornix macrohemorrhage in Wernicke-Korsakoff syndrome," Neurology, vol. 77, no. 22, article e129, 2011.

[41] J. M. Abarbanel, V. M. Berginer, A. Osimani, H. Solomon, and I. Charuzi, "Neurologic complications after gastric restriction surgery for morbid obesity," Neurology, vol. 37, no. 2, pp. 196200, 1987.

[42] G. Sechi, "Prognosis and therapy of Wernicke's encephalopathy after obesity surgery," American Journal of Gastroenterology, vol. 103, no. 12, article 3219, 2008.

[43] G. Sechi and A. Serra, "Wernicke's encephalopathy: new clinical settings and recent advances in diagnosis and management," The Lancet Neurology, vol. 6, no. 5, pp. 442-455, 2007.

[44] E. T. Aasheim, "Wernicke encephalopathy after bariatric surgery: a systematic review," Annals of Surgery, vol. 248, no. 5, pp. 714-720, 2008.

[45] J. P. Blass and G. E. Gibson, "Abnormality of a thiaminerequiring enzyme in patients with Wernicke-Korsakoff syndrome," The New England Journal of Medicine, vol. 297, no. 25, pp. 1367-1370, 1977.

[46] A. Ohnishi, S. Tsuji, H. Igisu et al., "Beriberi neuropathy. Morphometric study of sural nerve," Journal of the Neurological Sciences, vol. 45, no. 2-3, pp. 177-190, 1980. 


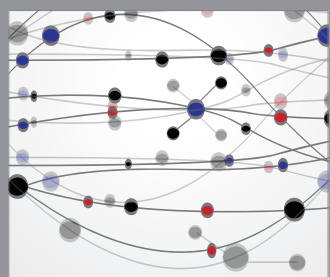

The Scientific World Journal
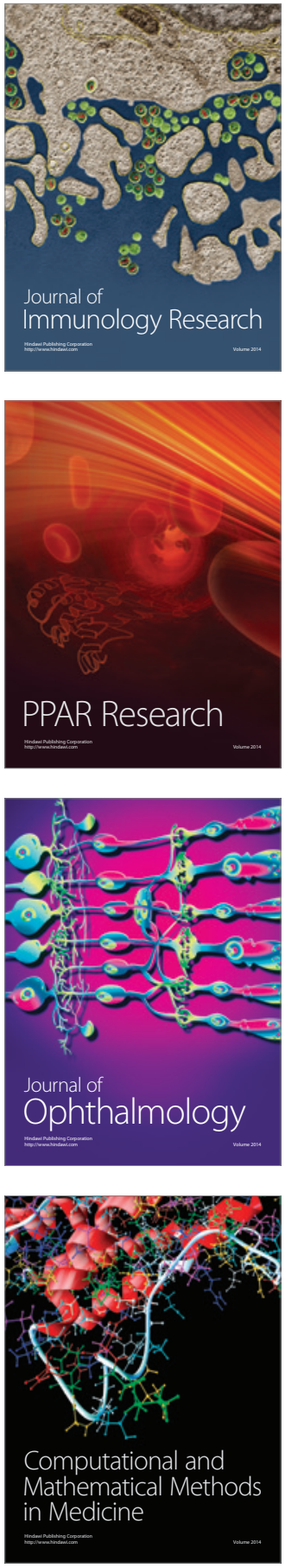

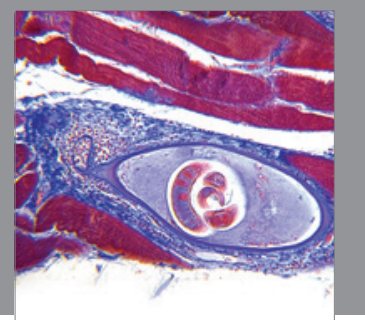

Gastroenterology

Research and Practice
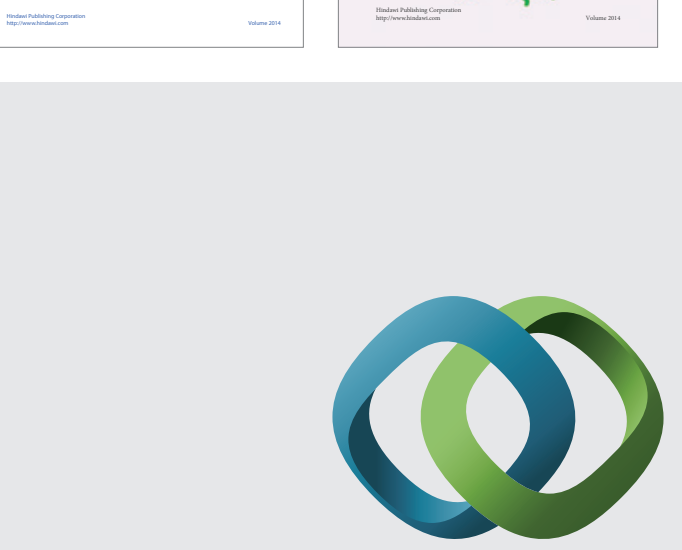

\section{Hindawi}

Submit your manuscripts at

http://www.hindawi.com
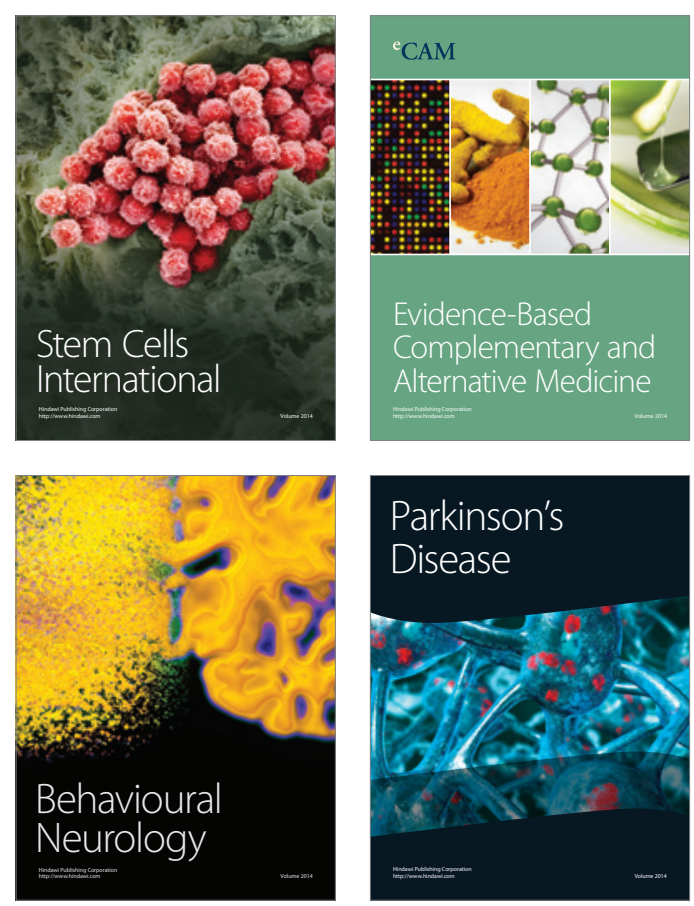

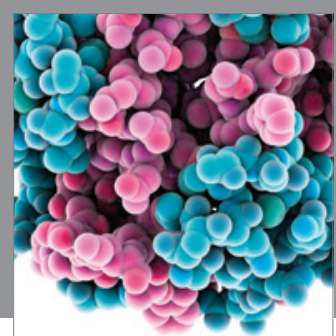

Journal of
Diabetes Research

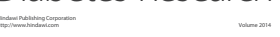

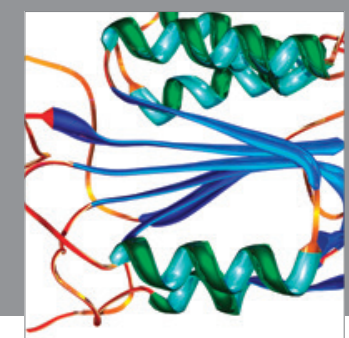

Disease Markers
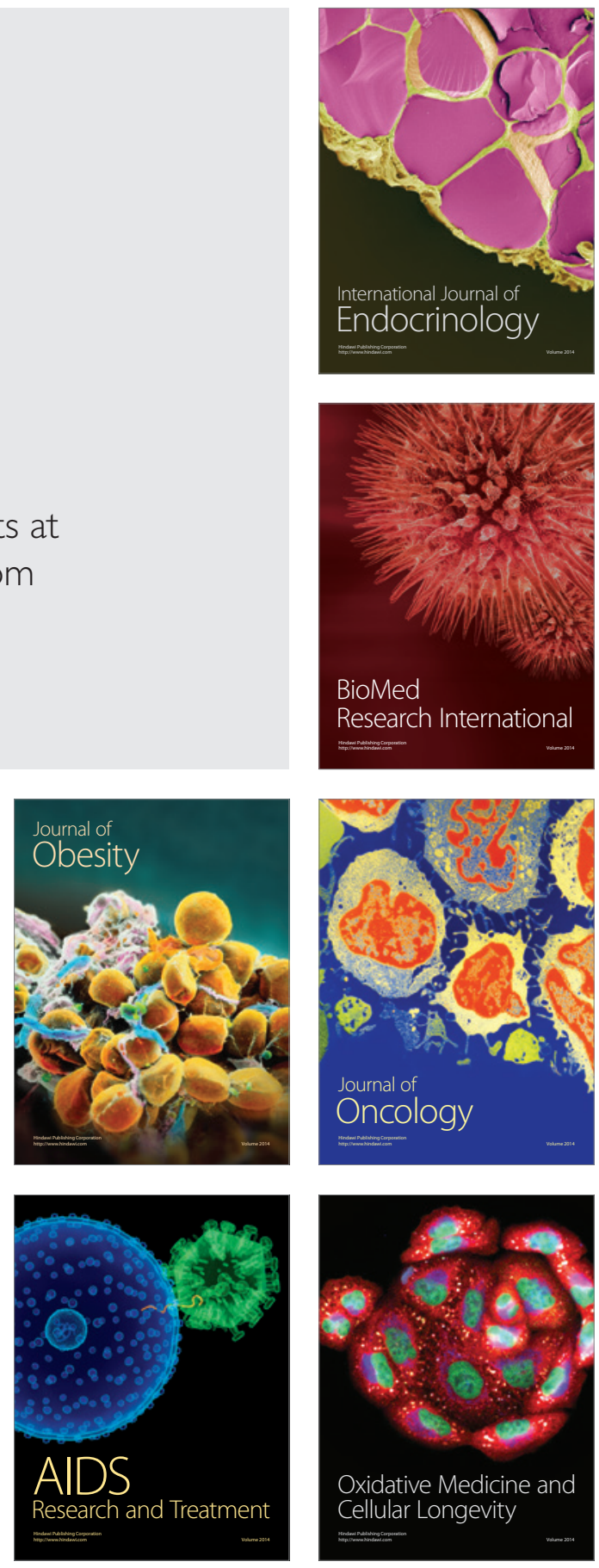